\title{
Development and validation of a real-time PCR for the detection and quantification of porcine circovirus type 2
}

\author{
Ana Margarida Henriques ${ }^{1}$ (i) Margarida Duarte $^{1} \cdot$ Sílvia Carla Barros $^{1} \cdot$

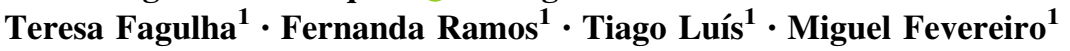

Received: 26 March 2018/ Accepted: 7 July 2018/Published online: 17 July 2018

(C) Indian Virological Society 2018

\begin{abstract}
Porcine circovirus type 2 (PCV2) is a spherical and non-enveloped virus belonging to the genus Circovirus of the Circoviridae family with a single stranded circular DNA genome. This virus, already detected worldwide, has been associated to several diseases and was implicated as the etiological agent of a disease named postweaning multisystemic wasting syndrome. Several methods have been described for the detection of PCV2, being real-time PCR the most simple and reliable. As far as we know, all the real-time PCR systems described until now are based on ORF2 gene, that exhibit the highest variability. This paper reports the development and validation of a real-time PCR targeted to ORF1 and based on a TaqMan probe for the detection of porcine circovirus type 2 DNA in swine samples. Due to the lack of PCV1 samples, the ability of the test to discriminate between PCV1 and PCV2 positive samples was evaluated in silico. Estimations of $100 \%$ specificity and $100 \%$ sensitivity were obtained based on the qPCR results with panel of 81 swine samples (known PCV2-positive ( $\mathrm{n}=50)$; known PCV2-negative $(\mathrm{n}=17)$; samples positive to other common swine viral pathogens $(\mathrm{n}=13)$ and one sample from a BFDV-positive parrot $(\mathrm{n}=1))$. Intra- and inter-assay coefficients of variation obtained with three positive samples of different viral charges in five replicates or in five independent assays were below the acceptance threshold. The limit of detection determined with a recombinant plasmid containing the
\end{abstract}

Ana Margarida Henriques

margarida.henriques@iniav.pt

1 Department of Virology, Instituto Nacional de Investigação Agrária e Veterinária, Av. da República, Quinta do Marquês, Oeiras, 2780-157 Lisbon, Portugal amplicon, led to conclude that this assay can detect at least three plasmid copies.

Keywords Porcine circovirus - Swine $\cdot$ Real-time PCR qPCR · TaqMan probe

\section{Introduction}

Classified within the genus Circovirus of the Circoviridae family, porcine circovirus type 2 (PCV2) was initially identified in a Canadian swine herd in 1991, and since then, has been implicated as the etiological agent of postweaning multisystemic wasting syndrome (PMWS) [1]. This disease of pigs is clinically characterised by growth retardation, paleness of skin, dyspnoea, enlargement of inguinal lymph nodes and occasionally jaundice and diarrhoea. Besides PMWS, other diseases have been associated to PCV2, namely porcine dermatitis and nephropathy syndrome (PDNS), reproductive failure, proliferative and necrotizing pneumonia, congenital tremors and central nervous system diseases [6]. PCV2 infection has a serious economic impact on the swine industry worldwide, having been diagnosed in the five continents [5]. Although mortality is comparatively low (4-20\%), morbidity can reach up to $50-60 \%$ in affected farms [15]. However, since vaccination was introduced in 2006 [4], the occurrence of PMWS has declined abruptly [13]. The presence of PCV2 in healthy pigs suggests that although the virus presence is crucial to induce PMWS, additional factors are also involved in the development of clinical disease [5].

PCV2 is spherical, non-enveloped and constitutes the smallest (17 nm of diameter) virus known until date. The genome, of about 1768 nucleotides, is circular and single stranded [11]. 
PCV2 was initially demonstrated by restriction fragment length polymorphism (RFLP) assays [3] and direct detection of viral antigen or DNA in tissue lesions by immunohistochemistry or in situ hybridization, respectively [12]. After that, quantitative PCR [2] and loop mediated isothermal amplification (LAMP) PCR [22] were reported for the identification of PCV2. More recently, DNA microarrays [8], as well as isothermal recombinase polymerase amplification assays, were described for the diagnosis of PCV2 in pigs [18]. Other real-time PCR reactions were reported [19-21], all of them based on ORF2, in which the variability observed among strains is higher than in ORF1. Moreover, one of the reactions [19] uses SYBR Green technology, less accurate, detecting a minimum of 1000 copies; while the other two, based on a TaqMan Probe exhibit limits of detection of 10 [21] and 25 [20]. The detection of PCV2 antibodies are commonly performed by ELISA using commercial kits.

This paper reports the development and validation of quantitative PCR (qPCR) for the detection of PCV2 in swine samples, using primers and a TaqMan probe directed to a conserved region of the replicase encoding gene (rep).

\section{Materials and methods}

\section{Primers and probe design}

A preliminary alignment was performed with full genomic sequences, representing the three genotypes (PCV2a, PCV2b and PCV2c). The replicase encoding gene (rep) was selected as target due to its lower nucleotide diversity among the strains analysed. Primers PCV2-PT-rep6(F) and PCV2-PT-rep149(R) with sequences 5'-CAGCAAGAAGAATGGAAG-3' and 5'-TTACCCTCCTCGCCAAC-3' respectively were selected (Table 1), allowing the amplification of a $144 \mathrm{bp}$ conserved region. A reverse-complement probe, leading to steeper curves was designed (PCV2PT-probe(R), with sequence 5'-FAM-TCCCGTATT TTCTTGCGCTCGTCTTC-TAMRA-3' (Table 1)).

A nucleotide alignment with about 1780 sequences available at GenBank (September 2017) that contain the 144 nt qPCR target sequence was performed, in order to carry out an in silico analysis of the primers and probe.

\section{qPCR}

A pool of organs including lymph nodes, lung, kidney, intestine, skin, spleen and tonsil from a PCV2-positive pig was used for viral DNA extraction, using a nucleic acid extraction workstation BioSprint 96 (Qiagen), according to manufacturer's instructions. Extracted DNA was used as template in the PCR. The reaction was performed with $500 \mathrm{ng}$ of total DNA, $25 \mathrm{pmol}$ of each primer and 5 pmol of probe, using the FastStart PCR Master Kit (Roche), according to the manufacturer's protocol. The amplification program included an initial denaturation at $95^{\circ} \mathrm{C}$ for $10 \mathrm{~min}$, followed by 45 cycles of denaturation at $95^{\circ} \mathrm{C}$ for $15 \mathrm{~s}$, annealing at $52^{\circ} \mathrm{C}$ for $30 \mathrm{~s}$ and extension at $60^{\circ} \mathrm{C}$ for 20 s. The qPCR machine used was the CFX96 real-time system associated to C1000 thermal cycle (Biorad).

\section{Sensitivity and specificity}

The sensitivity of the method was evaluated by testing 50 DNA samples confirmed PCV2 positive by other PCR method [14]. Samples from genotypes PCV2a and PCV2b, obtained between 2000 and 2010, were tested.

To evaluate the specificity of the test, 17 samples confirmed PCV2-negative by other PCR method [14] were assayed. The specificity was also evaluated by testing 13 samples positive for other swine diseases viruses, namely African swine fever virus (ASFV), classical swine fever virus (CSFV), European and American strains of porcine reproductive and respiratory syndrome virus (PRRSV), porcine epidemic diarrhea virus (PEDV), wild-type and $\mathrm{gE}$ deleted strains of pseudorabies virus (PRV), swine vesicular disease virus (SVDV), foot-and-mouth disease virus (FMDV), porcine parvovirus (PPV), swine influenza virus (SIV), swine coronavirus and swine rotavirus. Also, a positive sample of beak and feather disease virus, a circovirus from parrots, was tested [7]. Unfortunately, none sample of PCV1 was available, so the capability of the test to discriminate between the two types of PCV was only performed by in silico analysis.

In order to verify if the differences obtained between the $\mathrm{Ct}$ values of positive and negative samples were statistically significant, a statistical analysis was performed using the unpaired $t$ test with GraphPad Prism 5 Demo software. For the statistical analysis, the $\mathrm{Ct}$ (cycle threshold) value of
Table 1 Primer pair and TaqMan probe sequences designed for the detection of PCV2

\begin{tabular}{llc}
\hline Primer/probe & Sequence $\left(5^{\prime} \rightarrow 3^{\prime}\right)$ & Position $^{\text {a }}$ \\
\hline PCV2-PT-rep6(F) & CAGCAAGAAGAATGGAAG & $56-73$ \\
PCV2-PT-rep149(R) & TTACCCTCCTCGCCAAC & $199-183$ \\
PCV2-PT-probe(R) & TCCCGTATTTTCTTGCGCTCGTCTTC & $151-126$ \\
\hline
\end{tabular}

${ }^{\mathrm{a}}$ Numbering according PCV2 sequence HQ831540 
the negative samples was considered to be $\mathrm{Ct} 40$. Since the unpaired t-test cannot be performed in a set of equal values, one of the negative $\mathrm{Ct}$ values was assumed to be $\mathrm{Ct}$ 40.0001 .

\section{Repeatability evaluation}

The variation of a set of results obtained by a given sample was determined to evaluate the repeatability of the qPCR test. Both intra- and inter-assay variabilities were investigated through the analysis of the results obtained with a set of samples tested in replicates and in independent assays, respectively. To determine intra-assay variability, five replicates of three positive samples with different $\mathrm{Ct}$ (cycle threshold) values (low, medium and high $\mathrm{Ct}$ values) were tested in the same assay. On the other hand, inter-assay variability was evaluated by testing the three samples in five independent assays. In both cases, the coefficient of variation $(\% \mathrm{CV})$ was determined by dividing the standard deviation by the average of the $\mathrm{Ct}$ values obtained. The DNA sample used for the determination of the intra-assay variability for medium $\mathrm{Ct}$ value was not the same that the one used for the determination of the inter-assay variability.

\section{Determination of the limit of detection}

The limit of detection corresponds to the lowest number of copies detected in the qPCR reaction. To determine this limit, the assay was performed with ten-fold serial dilutions of an infectious clone (pCirc), previously constructed by our group. For the construction of pCirc, the complete genome of a PCV2 strain detected in our laboratory in 2005 (GenBank accession number HQ831532) was amplified using reverse complement overlapping primers, $\mathrm{SacF}$ (5'GAACCGCGGGCTGGCTGAACTTTTGAAAGT-3') and SacR (5'-GCACCGCGGAAATTTCTGACAAACGTT ACA-3'), including the SacII restriction site. The amplicon was cloned into the pCR2.1 vector (Invitrogen), originating the TA-CircSac recombinant. Another fragment of $850 \mathrm{bp}$ comprising the region between EcoRI and SacII restriction sites, amplified with primers EcoF (5'-GCGGAATTCAACCTTAACCTTTCTTATTCT- $3^{\prime}$ ) and $S a c R$, was cloned into pEGFP vector (Clontech), giving rise to pCircEcoSac. The infectious clone was constructed after restriction of both plasmids with SacII restriction enzyme by cloning CircSac fragment of TA-CircSac into pCircEcoSac, using One Shot TOP10F' chemically competent Escherichia coli (Invitrogen), originating pCirc. The plasmid, with a total size of $7325 \mathrm{bp}$, was extracted using the Plasmid Midi Purification kit (Qiagen) and the concentration was determined by spectrophotometry at $260 \mathrm{~nm}$. The concentration of the stock solution was $1.25 \times 10^{-6} \mathrm{~g} / \mu \mathrm{l}$.
The mass of one molecule of pCirc was determined using the formula:

$$
\begin{aligned}
\mathrm{m} & =7325 \mathrm{bp} \times \frac{1 \mathrm{~mol}}{6.023 \times 10^{23} \text { molecules }} \times \frac{660 \mathrm{~g} / \mathrm{bp}}{1 \mathrm{~mol}} \\
& =8.03 \times 10^{-18} \mathrm{~g} / \text { molecule }
\end{aligned}
$$

Ten-fold serial dilutions were prepared, starting with $3 \times 10^{5}$ plasmid copies $\left(2.4 \times 10^{-12} \mathrm{~g}\right)$, until one plasmid copy per reaction was present. The qPCR assay was performed with duplicates for each concentration.

\section{Results and discussion}

\section{Primers and probe design}

For the in silico analysis, primers and probe sequences were aligned with all the PCV2 sequences available in GenBank (September 2017). From the 1787 sequences containing the region complement to PCV2-PTrep6(F) forward primer, only 14 sequences $(0.78 \%)$ may fail amplification due to a mutation in the first $(\mathrm{n}=12$, $0.67 \%)$ or second $(n=2,0.11 \%)$ nucleotide of the $3^{\prime}$ end. These 14 sequences are originated from China $(\mathrm{n}=8$, $0.45 \%)$, Cuba $(\mathrm{n}=2,0.11 \%)$, South Korea $(\mathrm{n}=2,0.11 \%)$, India $(\mathrm{n}=1 ; 0.06 \%)$ and Malaysia $(\mathrm{n}=1,0.06 \%)$. Concerning PCV2-PT-rep149(R) reverse primer, from the 1790 sequences available, four sequences $(0.22 \%)$ originated from Eastern countries (China $(\mathrm{n}=2,0.11 \%)$, India $(\mathrm{n}=1$, $0.06 \%)$ and Australia $(\mathrm{n}=1,0.06 \%)$ ), presented a mutation in the second nucleotide of the $3^{\prime}$ end. In two sequences $(0.11 \%)$ from China (GenBank accession numbers KJ680360 and GU325763), more mismatches were identified with only eight nucleotides being preserved on the central region of this primer, hampering the detection of these strains by the method.

The higher variability was observed within PCV2-PTprobe complement sequences. However, most of the sequences $(188,10.56 \%)$ from the 1780 sequences available differ in one unique nucleotide, the large majority ( $\mathrm{n}=156,8.76 \%$ ) located in the third nucleotide of the $3^{\prime}$ end. The single mutation is distributed in other several nucleotide positions of the probe sequence in the remaining 32 strains $(1.80 \%)$. Only eight sequences $(0.45 \%)$ present 2 mutations ( $92.3 \%$ similarity), and in sequence KJ680360 $(0.06 \%)$ six mutations are observed. Except for six strains from South Korea (KX828220/33/34/35, JF317566/8), three from Canada (AF086835, DQ220732, EU747085), two from the USA (AY099497 and KR816332), two from India (LC004740/52), two from Brazil (KT819159/70) and one from Japan (KR054744), Malaysia (JF690918), Indonesia (KT369068), Denmark (EU148507), Sweden (EU386606) and Portugal (HQ831528), all the strains 
exhibiting mutations in relation to the probe originated in China, and were collected between 2004 and 2016. For these reasons, we can conclude that this system is able to detect the vast majority of the strains.

According to several authors $[9,10,16]$, depending on the location, one or two mutations in primers or probe may reduce the sensitivity of the PCR but not prevent amplification. In most cases, no effect is noted due to mutations in primers or probe. Strain HQ831528 from Portugal, detected in our lab in 2006, presents one mutation in nucleotide six from the $3^{\prime}$ end. The real-time PCR method described in this paper was performed with DNA from this strain, and an amplification curve with Ct 19.9 was obtained, confirming that such mutation in the probe annealing sequence had no effect in the reaction.

\section{Sensitivity and specificity}

Specificity corresponds to the proportion of negative samples which are correctly identified by the test. To assess the specificity of the PCR, 17 negative samples were assayed, all testing negative. The specificity of the test was also evaluated by its capacity to generate negative results with samples positive for other swine viruses. Swine samples positive to 13 other virus pathogens (African swine fever virus (ASFV), classical swine fever virus (CSFV), European and American strains of porcine reproductive and respiratory syndrome virus (PRRSV), porcine epidemic diarrhoea virus (PEDV), wild-type and $\mathrm{gE}$ deleted strains of pseudorabies virus (PRV), swine vesicular disease virus (SVDV), foot-and-mouth disease virus (FMDV), porcine parvovirus (PPV), swine influenza virus (SIV), swine coronavirus and swine rotavirus) and a positive sample of beak and feather disease virus, a circovirus from parrots, tested negative in the qPCR further demonstrating $100 \%$ specificity of the test. No PCV1 sample was available to test the capability of the test to discriminate between the two types of porcine circovirus, however, an in silico analysis revealed that both primers and probe cannot recognize PCV1 nucleotide samples.

The sensitivity of the test reported here was evaluated by measuring the proportion of positive samples correctly identified by the qPCR. For this purpose, 50 DNA samples testing PCV2-positive by other method were assayed. Since all the samples tested positive in this qPCR, the overall results reveal a sensitivity of $100 \%$.

Figure 1 represents the $\mathrm{Ct}$ values obtained in the PCR test for positive $(n=50)$ and negative $(n=31)$ DNA samples. The $P$ value obtained was lower than 0.0001 $(P<0.0001)$, confirming that the two groups are statistically different.

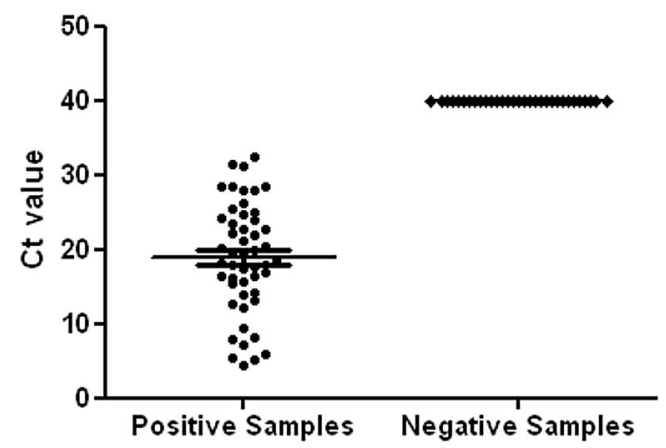

Fig. 1 Representation of $\mathrm{Ct}$ values obtained in the PCR test for positive $(n=50)$ and negative $(n=31)$ DNA samples. For negative samples, the $\mathrm{Ct}$ value was considered to be $\mathrm{Ct}=40$, but since the unpaired t-test cannot be performed in a set of equal values, one of the negative $\mathrm{Ct}$ value was assumed to be $\mathrm{Ct}=40.0001$. The averages of $\mathrm{Ct}$ values as well as the standard deviation are represented. Means and respective standard errors $(\mathrm{SEM})$ were $18.86 \pm 1.040(\mathrm{n}=50)$ for positive samples and $40 \pm 0.000(\mathrm{n}=31)$ for negative DNA samples

\section{Repeatability evaluation}

The intra- and inter-plate precisions were evaluated by testing three positive DNA samples with different viral charges in five replicates in the same assay or in five independent assays, respectively. In both cases, precision was expressed as a percentage of the coefficient of variation of the Ct values obtained. Table 2 shows the coefficients of variability obtained with the samples used in the intra- and inter-plate precision evaluations.

The intra-plate variability determined with DNA samples of three different viral charges was very low for each sample tested. DNA sample of low viral charge originated $\% \mathrm{CV}$ slightly higher $(\mathrm{CV}=0.97 \%)$ than the other two DNA samples $(\mathrm{CV}=0.72 \%$ and $\mathrm{CV}=0.71 \%)$, but still lower than 1. As expected, the inter-plate variability or reproducibility observed with each of the samples tested was higher than the intra-plate variability, since more factors can vary between each assay. In this case, the DNA sample of high viral charge originated a lower \%CV $(\mathrm{CV}=1.00 \%)$ than the other two samples $(\mathrm{CV}=2.04 \%$ and $\mathrm{CV}=2.03 \%$ ).

The results obtained indicate that the qPCR is highly repeatable and reproducible.

\section{Determination of the limit of detection}

The limit of detection is defined as the smallest amount of plasmid copies detectable in the assay. For the determination of this limit, a plasmid containing the fragment to be amplified in the PCR reaction and with known concentration is tested in serial dilutions. The limit of detection corresponds to the minimum number of copies that can be detected in the reaction. 
Table 2 Intra- and inter-plate precision evaluations based on the coefficients of variability (CV) obtained with one sample in five independent assays or with three samples of different viral charges in the same assay (5 replicates)

\begin{tabular}{|c|c|c|c|c|c|c|}
\hline \multirow[t]{2}{*}{ Sample } & \multicolumn{3}{|c|}{ Variability intra-plate } & \multicolumn{3}{|c|}{ Variability inter-plate } \\
\hline & Sample 1 & Sample $2^{\mathrm{a}}$ & Sample 3 & Sample 1 & Sample $4^{\mathrm{a}}$ & Sample 3 \\
\hline Replicate 1 & 16.96 & 21.99 & 33.01 & 16.76 & 21.09 & 32.69 \\
\hline Replicate 2 & 16.84 & 22.13 & 33.21 & 17.06 & 21.63 & 31.96 \\
\hline Replicate 3 & 16.89 & 21.82 & 33.87 & 17.19 & 21.59 & 31.45 \\
\hline Replicate 4 & 17.05 & 22.2 & 33.38 & 17.16 & 20.69 & 31.76 \\
\hline Replicate 5 & 16.73 & 22.16 & 33.48 & 17.05 & 20.82 & 33.01 \\
\hline Average & 16.89 & 22.06 & 33.39 & 17.04 & 21.16 & 32.17 \\
\hline Standard deviation & 0.12 & 0.16 & 0.32 & 0.17 & 0.43 & 0.65 \\
\hline CV (\%) & 0.72 & 0.71 & 0.97 & 1.00 & 2.04 & 2.03 \\
\hline
\end{tabular}

${ }^{a}$ The DNA samples used for the determination of the intra- and inter-assay variabilities for medium $\mathrm{Ct}$ values was not the same due to the lack of available DNA
The infectious clone pCirc was tested in the real-time PCR method in seven ten-fold serial dilutions, starting at $3 \times 10^{5}$ plasmid copies and until one plasmid copy was expected to be present. The assay was performed in duplicate and the $\mathrm{Ct}$ values obtained were registered. The curves obtained in the q PCR are represented in Fig. 2.

The only concentration at which no DNA amplification was achieved was one plasmid copy, and therefore the limit of detection determined was three plasmid copies, since it was the smallest concentration at which DNA was still detected.

A calibration line was obtained by the representation of the $\mathrm{Ct}$ values as a function of the logarithm of the copy number (Fig. 3). A correlation coefficient of 0.998 was obtained. Since Ct increases with decreasing number of plasmid copies, the slope is negative. For ten-fold serial dilutions the slope is -3.33 when $\mathrm{E}=100 \%$, considering that a perfect doubling of the number of DNA molecules occurs [17]. In this case an acceptable slope of -3.576 , corresponding to a PCR efficiency of $90.4 \%$ (given by the expression $\left.E=\left(10^{-(1 / \text { slope })}-1\right) * 100\right)$ was obtained.

A qPCR based on a TaqMan probe was developed for the molecular diagnosis of PCV2 in swine samples.

Both sensitivity and specificity were assessed in $100 \%$, revealing the full capacity of the test to differentiate a positive from a negative PCV2-DNA sample even when low viral charges are present. Moreover, samples positive for other swine viruses or for a circovirus from another species tested negative in this PCR assay, demonstrating the specificity of the test.

The precision intra- and inter-assay determined with three positive DNA samples of different viral charges in five replicates or in five independent assays, showed CV well below the acceptable limit, indicating that a test has good repeatability and reproducibility.

The test performed with a plasmid containing the fragment to be amplified in the qPCR, with known
PCR Amp/Cycle Graph for FAM-490

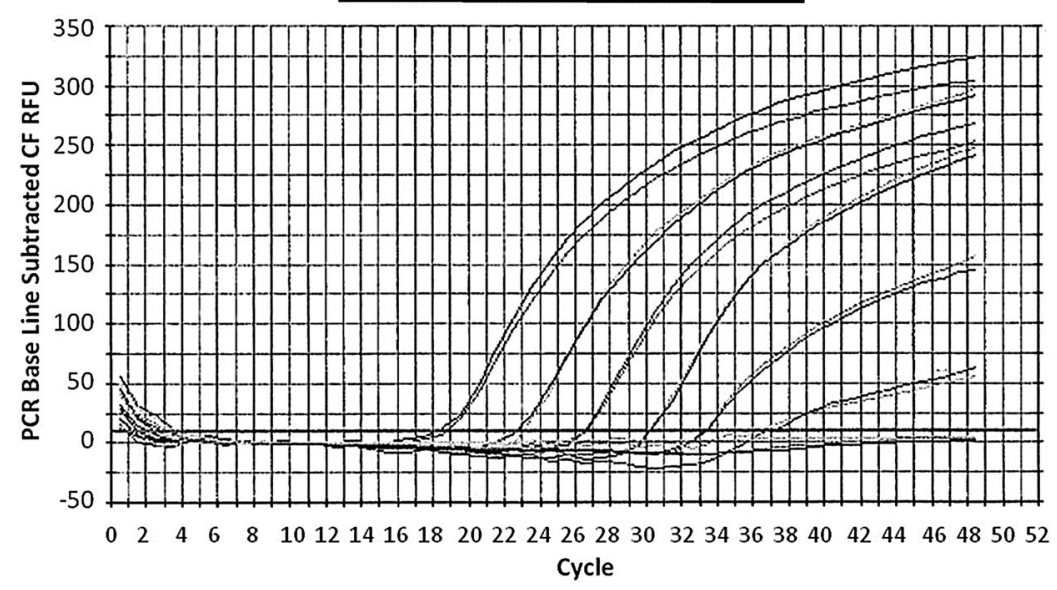

\begin{tabular}{rcc} 
Plasmid copies & \multicolumn{2}{c}{ Ct values } \\
\cline { 2 - 3 } number & Replicate1 & Replicate 2 \\
\hline 300000 & 18.21 & 18.73 \\
30000 & 23.02 & 22.67 \\
3000 & 26.66 & 26.54 \\
300 & 30.19 & 30.21 \\
30 & 33.21 & 33.30 \\
3 & 36.29 & 36.78 \\
1 & No Ct & No Ct \\
\hline
\end{tabular}

Fig. 2 Amplification curves obtained in the real-time PCR reaction performed for the determination of the limit of detection. Duplicates of seven ten-fold serial dilutions of the infectious clone pCirc, starting at $3 \times 10^{5}$ plasmid copies and until 1 plasmid copy were assayed. $\mathrm{Ct}$ values obtained for each replicate are indicated in the table at the right side 


\section{Correlation Coefficient: 0.998 Slope: $-\mathbf{3 . 5 7 6}$ Intercept: $38.631 \quad Y=-3.576 X+38.631$ PCR Efficiency: $90.4 \%$}

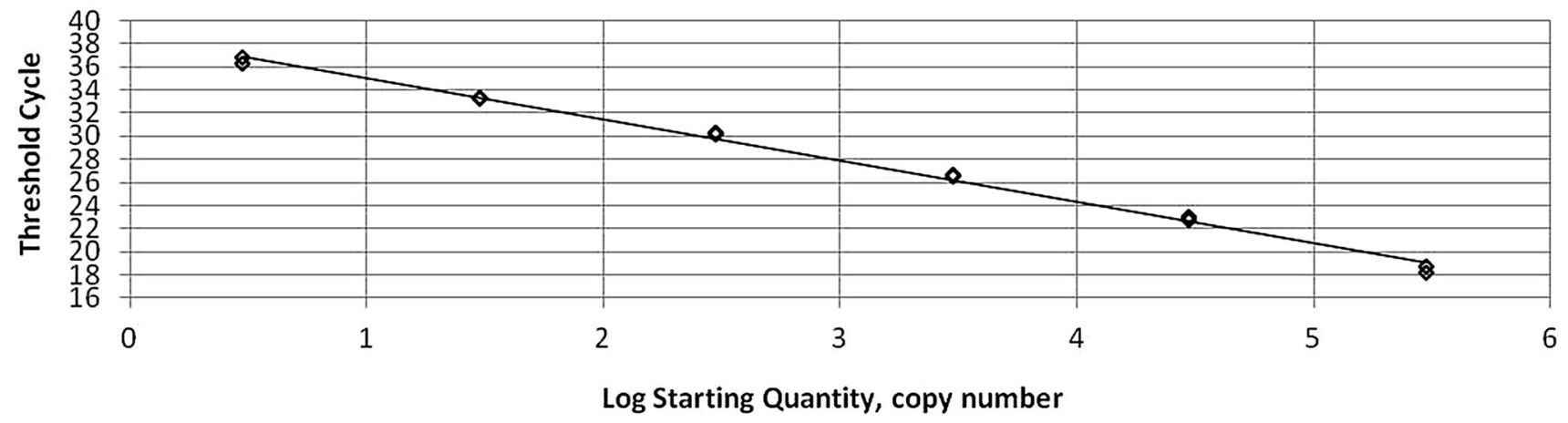

Fig. 3 Calibration curve obtained by the representation of the $\mathrm{Ct}$ values as a function of the logarithm of the plasmid copies number

concentration in serial dilutions led to conclude that this assay can detect a minimum of three plasmid copies.

This method is used in our laboratory since 2007 in routine analysis and has proven to be a reliable molecular method for the detection of porcine circovirus in pigs.

Acknowledgements The authors thank Arminda Batista, Ana Santos, Fátima Cordeiro, Ricardino Ferreira, Maria João Teixeira and Rosário Ferreira for excellent technical support. This research did not receive any specific grant from funding agencies in the public, commercial, or not-for-profit sectors.

\section{References}

1. Cheung AK. The essential and nonessential transcription units for viral protein synthesis and DNA replication of porcine circovirus type 2. Virology. 2003;313(2):452-9.

2. Chung WB, Chan WH, Chaung HC, Lien Y, Wu CC, Huang YL. Real-time PCR for quantitation of porcine reproductive and respiratory syndrome virus and porcine circovirus type 2 in naturally-infected and challenged pigs. J Virol Methods. 2005;124(1-2):11-9.

3. Ciacci-Zanella JR, Mores N. Diagnosis of post-weaning multisystemic wasting syndrome in pigs in Brazil caused by porcine circovirus type 2. Arq Bras Med Vet Zoo. 2003;55(5):522-7.

4. da Silva N, Carriquiry A, O’Neill K, Opriessnig T, O'Connor AM. Mixed treatment comparison meta-analysis of porcine circovirus type 2 (PCV2) vaccines used in piglets. Prev Vet Med. 2014;117(3-4):413-24.

5. Grau-Roma L, Fraile L, Segales J. Recent advances in the epidemiology, diagnosis and control of diseases caused by porcine circovirus type 2 . Vet J. 2011;187(1):23-32.

6. Harding JC. The clinical expression and emergence of porcine circovirus 2. Vet Microbiol. 2004;98(2):131-5.

7. Henriques AM, Fagulha T, Duarte M, Ramos F, Barros S, Luis T, Bernardino R, Fevereiro M. Phylogenetic analysis of six isolates of beak and feather disease virus from african grey parrots in Portugal. Avian Dis. 2010;54(3):1066-71.

8. Jiang YH, Guo Y, Wang P, Dong QF, Opriessnig T, Cheng JH, $\mathrm{Xu} \mathrm{H}$, Ding XF, Guo JF. A novel diagnostic platform based on multiplex ligase detection-PCR and microarray for simultaneous detection of swine viruses. J Virol Methods. 2011;178(1-2):171-8.
9. Kim LM, Afonso CL, Suarez DL. Effect of probe-site mismatches on detection of virulent Newcastle disease viruses using a fusion-gene real-time reverse transcription polymerase chain reaction test. J Vet Diagn Invest. 2006;18(6):519-28.

10. Klungthong $C$, Chinnawirotpisan $P$, Hussem $K$, Phonpakobsin $T$, Manasatienkij W, Ajariyakhajorn C, Rungrojcharoenkit K, Gibbons RV, Jarman RG. The impact of primer and probe-template mismatches on the sensitivity of pandemic influenza $\mathrm{A} / \mathrm{H} 1 \mathrm{~N} 1 /$ 2009 virus detection by real-time RT-PCR. J Clin Virol. 2010;48(2):91-5.

11. Mahe D, Blanchard P, Truong C, Arnauld C, Le Cann P, Cariolet R, Madec F, Albina E, Jestin A. Differential recognition of ORF2 protein from type 1 and type 2 porcine circoviruses and identification of immunorelevant epitopes. J Gen Virol. 2000;81(Pt 7):1815-24.

12. McNeilly F, Kennedy S, Moffett D, Meehan BM, Foster JC, Clarke EG, Ellis JA, Haines DM, Adair BM, Allan GM. A comparison of in situ hybridization and immunohistochemistry for the detection of a new porcine circovirus in formalin-fixed tissues from pigs with post-weaning multisystemic wasting syndrome (PMWS). J Virol Methods. 1999;80(2):123-8.

13. Nielsen GB, Nielsen JP, Haugegaard J, Denwood MJ, Houe H. Effect of vaccination against sub-clinical porcine circovirus type 2 infection in a high-health finishing pig herd: a randomised clinical field trial. Prev Vet Med. 2017;141:14-21.

14. Ouardani M, Wilson L, Jette R, Montpetit C, Dea S. Multiplex PCR for detection and typing of porcine circoviruses. J Clin Microbiol. 1999;37(12):3917-24.

15. Segales J. Porcine circovirus type 2 (PCV2) infections: clinical signs, pathology and laboratory diagnosis. Virus Res. 2012;164(1-2):10-9.

16. Suss B, Flekna G, Wagner M, Hein I. Studying the effect of single mismatches in primer and probe binding regions on amplification curves and quantification in real-time PCR. J Microbiol Methods. 2009;76(3):316-9.

17. Svec D, Tichopad A, Novosadova V, Pfaffl MW, Kubista M. How good is a PCR efficiency estimate: recommendations for precise and robust qPCR efficiency assessments. Biomol Detect Quantif. 2015;3:9-16.

18. Yang Y, Qin X, Sun Y, Cong G, Li Y, Zhang Z. Development of isothermal recombinase polymerase amplification assay for rapid detection of porcine circovirus type 2. BioMed Res Int. 2017;2017:1-8.

19. Yang Z-Z, Habib M, Shuai J-B, Fang W-H. Detection of PCV2 DNA by SYBR Green I-based quantitative PCR. J Zhejiang Univ Sci B. 2007;8(3):162-9. 
20. Yuan WZ, Li JF, Li LM, Sun MT, Zheng YS, Qi Y, Sun JG, Song QY. Rapid detection of porcine circovirus type 2 by TaqManbased real-time polymerase chain reaction assays. Int J Appl Res Vet Med. 2014;12(3):214-20.

21. Zhao K, Han FT, Zou Y, Zhu LL, Li CH, Xu Y, Zhang CL, Tan FR, Wang JB, Tao SR, He XZ, Zhou ZQ, Tang XM. Rapid detection of porcine circovirus type 2 using a TaqMan-based realtime PCR. Virol J. 2010;7:374.

22. Zhou S, Han S, Shi JL, Wu JQ, Yuan XY, Cong XY, Xu SJ, Wu $\mathrm{XY}$, Li J, Wang JB. Loop-mediated isothermal amplification for detection of porcine circovirus type 2. Virol J. 2011;8:497. 